\title{
Effect of Long-Term Osmotic Loading Culture on Matrix Synthesis from Intervertebral Disc Cells
}

\author{
Grace D. O'Connell, ${ }^{1}$ Isabella B. Newman, ${ }^{2}$ and Michael A. Carapezza ${ }^{2}$
}

\begin{abstract}
The intervertebral disc is a highly hydrated tissue that acts to absorb and distribute large complex loads placed on the spine. Diurnal loading and disc degeneration causes significant changes in water volume and proteoglycan content, which alters the internal osmotic environment. Short-term osmotic loading alters disc cell gene expression; however, the long-term effect of osmotic loading on disc cell matrix synthesis is not well understood. The objective of this study was to determine the effect of long-term osmotic loading on matrix turnover and proliferation by juvenile and adult cells from the nucleus pulposus (NP) and the cartilaginous endplate (EP). Matrix synthesis was evaluated using pellets and a 3D agarose system, which has been used for developing engineered tissues. Intervertebral discs were acquired from juvenile and adult cows. Cells were acquired through enzymatic digestion and expanded in culture. Pellets were formed through centrifugation, and constructs were created by encapsulating cells within $2 \% \mathrm{w} / \mathrm{v}$ agarose hydrogel. Pellets and constructs were cultured up to 42 days in chemically defined medium with the osmolality adjusted to 300,400 , or $500 \mathrm{mOsm} / \mathrm{kg}$. EP cells were evaluated as a chondrocyte comparison to chondrocyte-like NP cells. Pellet and agarose cultures of juvenile NP and EP cells demonstrated similarities with respect to cell proliferation and functional mechanical properties. Cell proliferation decreased significantly with increased osmotic loading. The final compressive Young's modulus of juvenile NP cells was $10-40 \times$ greater than initial properties (i.e., day 0 ) and was greater than the final Young's modulus of adult NP and juvenile EP constructs. In juvenile NP constructs, there were no significant differences in GAG content with respect to osmotic loading. However, GAG synthesis and mechanical properties were greatest for the $400 \mathrm{mOsm} / \mathrm{kg}$ group in adult NP constructs. Taken together, the results presented here suggest a tradeoff between cell proliferation and matrix production under osmotic loading conditions. In conclusion, culturing disc cells in an osmotic environment that best mimics the healthy disc environment $(400 \mathrm{mOsm} / \mathrm{kg}$ ) may be ideal for balancing cell proliferation, matrix production, and mechanical properties of engineered disc tissues.
\end{abstract}

Key words: nucleus pulposus cells; endplate cells; intervertebral disc; pellet culture; agarose culture; aging; regeneration

\section{Introduction}

$\mathbf{T}$ HE INTERVERTEBRAL DISC is the fibrocartilaginous soft tissue of the spine located between vertebrae. The primary function of the disc is to absorb and distribute large complex loads placed on the spine and to provide flexibility. It is a thick ( $\sim 10 \mathrm{~mm}$ in the lumbar spine) avascular tissue comprised of a gelatinous nucleus pulposus (NP) surrounded by the stiffer annulus fibrosus. ${ }^{1-4}$ The internal osmotic environment of the disc is altered with diurnal loading and degeneration and may affect extracellular matrix production and turnover; however, much of the work done with osmotic loading on disc cells has been performed in short-term monolayer culture (i.e., $<1$ week in culture). ${ }^{5,6}$ Techniques developed for tissue engineering and regeneration can be utilized for understanding disc degeneration by evaluating cell behavior and matrix deposition in a three-dimensional (3-D) environment that mimics the in situ environment.

Changes in water content or proteoglycan content with daily loading, degeneration, or injury can greatly alter the intradiscal osmotic environment. The NP is comprised mostly of water $(80 \%)$, proteoglycans $(60 \%-70 \%$ per wet weight [\%/ww]), collagens (30\%/ww) and is populated with NP cells with chondrocyte-like characteristics. ${ }^{7-10}$ Approximately $25 \%$

\footnotetext{
${ }^{1}$ Department of Mechanical Engineering, University of California, Berkeley, California.

${ }^{2}$ Department of Biomedical Engineering, Columbia University, New York, New York.
} 


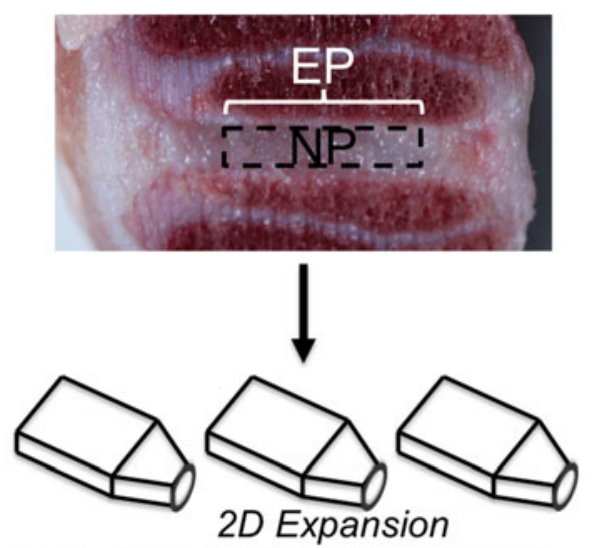

Media: (DMEM, 10\% FBS, $1 \mathrm{ng} / \mathrm{ml} \mathrm{TGF \beta 1}$, $10 \mathrm{ng} / \mathrm{ml}$ PDGF $\beta \beta$, and $5 \mathrm{ng} / \mathrm{ml} \mathrm{FGF2)}$
FIG. 1. Schematic of study design using disc cells from the nucleus pulposus (NP) and cartilaginous endplate (EP). The effect of long-term osmotic loading and growth factor supplementation on disc cells were evaluated using three-dimensional pellet cultures.

\section{Pellet Culture}<smiles>O=C1C=CC=C1</smiles>
$300 \mathrm{mOsm}$
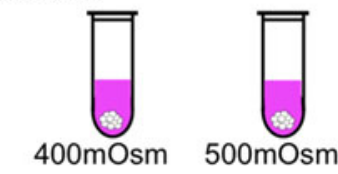

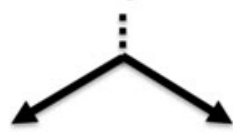

Hydrogel Culture

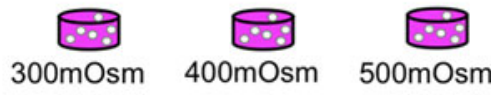

of the disc's fluid is expelled and re-imbibed during each diurnal cycle. ${ }^{11}$ The lower water content at the end of a diurnal loading cycle significantly alters the osmotic environment from approximately $400 \mathrm{mOsm} / \mathrm{kg}$ at maximum hydration to $550 \mathrm{mOsm} / \mathrm{kg} .{ }^{1-13}$ Negatively charged proteoglycans allow the tissue to recruit water molecules during recovery, restoring the osmotic balance. Moderate disc degeneration is noted by a decrease in water and proteoglycan content and a loss in full recovery from diurnal loading, which may further alters the osmotic loading environment. ${ }^{7,14-17}$ Chondrocytes behave as a perfect osmometer, where the cell volume significantly decreases with increasing osmotic loading. Fluctuations in osmolality with diurnal loading and degeneration alter the local stresses placed on the cells and may alter matrix production and turnover. ${ }^{5}$

Cell morphology varies greatly throughout the disc, with chondrocytes in the cartilaginous endplate and fibroblast-like cells in the annulus fibrosus. ${ }^{8}$ The healthy juvenile NP is populated with notochordal cells, which disappears with age (by 10 years in humans) and is replaced with chondrocyte-like NP cells. ${ }^{18}$ However, long-term in vitro studies with notochordal cells has been a challenge, as the ratio of notochordal cells to NP cells decreases with culture time, which may be due to a difference in cell proliferation rates. ${ }^{19-21}$

Recent studies demonstrated that osmolality alters cell proliferation, gene expression and matrix production of NP cells. ${ }^{6,12}$ Takeno et al. demonstrated that aggrecan and collagen type 2 synthesis from adult bovine NP cells increased when cultured in medium that represented the in vivo osmotic environment of healthy discs $(400 \mathrm{mOsm} / \mathrm{kg}){ }^{22} \mathrm{In}$ contrast, NP cell gene expression was lower in $300 \mathrm{mOsm} /$ $\mathrm{kg}$, which is comparable to the osmolality of purchased high glucose Dulbecco's modified Eagle medium (DMEM; Sigma-Aldrich, Inc.). ${ }^{12,14,22}$ However, these studies have been limited to understanding the short-term effect of osmotic loading on cell response and matrix production (i.e.,
$<1$ week). Long-term studies are needed to elucidate the effect of osmotic loading on tissue growth and remodeling. Moreover, based on osmotic environmental differences with age and degeneration, cell response, and tissue growth due to osmotic loading may be age dependent.

Matrix production and tissue growth from cells obtained from older donors or diseased tissues is a significant challenge for regenerative medicine.* As research moves toward developing biological repair strategies for the disc, it will be crucial to understand age-dependent changes with matrix turnover and tissue maintenance. Therefore, the objective of this study was to determine the effect of long-term osmotic loading on matrix turnover and proliferation by juvenile and adult disc cells from the NP and the cartilaginous endplate (EP). We hypothesize that long-term osmotic loading conditions will alter matrix deposition, tissue growth, and mechanical properties of engineered tissues. In this study, matrix synthesis was evaluated using two 3-D culture systems (i.e., pellet and 3-D hydrogel cultures). Pellets are beneficial for evaluating various culture conditions with a relatively low cell numbers $\left(\sim 20 \times 10^{6}\right.$ cells per pellet study versus $180 \times 10^{6}$ cells per agarose study) and providing data that can be compared to previous monolayer culture studies, ${ }^{5,6,23}$ since cell-cell interactions are preserved. However, the disc's primary function is to absorb and distribute the large complex loads placed on the spine during diurnal loading; therefore, A 3-D hydrogel system was also used to assess mechanical properties of the matrix synthesized by disc cells.

\section{Materials and Methods}

Lumbar spine sections from juvenile cows (3-6 weeks) were acquired and the intervertebral discs were removed

*O'Connell GD, Tan AR, Palmer G, et al. Cell migration behavior of human chondrocytes for guiding three dimensional engineered cartilage growth. In review. 
aseptically with a scalpel, and the annulus fibrosus, NP, and EP were separated (Fig. 1). Caudal spine sections were acquired from adult cows (18 months), and the NP tissue was removed from the annulus fibrosus with a scalpel. The EP in adult discs was too thin to accurately and reliably separate from NP tissue; therefore, only NP cells were used for tissue culture studies. NP and EP tissues were digested in highglucose DMEM supplemented with 1M 4-(2-hydroxyethyl)1-piperazineethanesulfonic acid (HEPES, Invitrogen Co.) supplemented with $5 \%$ fetal bovine serum (FBS, Atlanta Biologicals), 1M 2-[[1,3-dihydroxy-2-(hydroxymethyl)propan2-yl]amino]ethanesulfonic acid (TES, Sigma-Aldrich), 1M 2-[Bis(2-hydroxyethyl)amino]ethanesulphonic acid (BES, Sigma-Aldrich), 1M HEPES, $1 \%$ nonessential amino acids, $2 \%$ minimum essential amino acids, sodium bicarbonate, $1 \%$ antibiotic-antimyotic, and collagenase (Worthington) for 11 hours at $37^{\circ} \mathrm{C}$ with stirring. The digested tissue and media was filtered using a $70 \mu \mathrm{m}$ filter. For each experimental run, cells from four discs were pooled together for expansion, and then each experiment was repeated to ensure robustness of the results.

Cells were expanded for two passages (plating density = 45,000 cells $/ \mathrm{cm}^{2}$ ) in DMEM media containing $10 \% \mathrm{FBS}$, $100 \mathrm{U} / \mathrm{mL}$ penicillin, and $100 \mathrm{mg} / \mathrm{mL}$ streptomycin and amphotericin B, $0.5 \mathrm{ng} / \mathrm{mL}$ basic fibroblast growth factor, $0.5 \mathrm{ng} / \mathrm{mL}$ platelet-derived growth factor, and $1 \mathrm{ng} / \mathrm{mL}$ of TGF- $\beta 1$ (Invitrogen Co.) (Fig. 1). ${ }^{24}$ Cells were passaged to obtain an adequate cell population for 3-D studies and to ensure a homogeneous cell population from the juvenile bovine donor NP tissues. Once the cells were confluent, they were detached through trypsinization (trypsin EDTA; Cellgro Mediatech, Inc.) for use in pellet and agarose studies. Expansion media was changed three times a week.

\section{Study 1: Pellet culture}

Disc cells were cultured in micropellet cultures, which were formed by centrifugation of the passaged cells $(500,000$ cells/pellet, 2,500 rpm for 10 minutes at $25^{\circ} \mathrm{C}$ ). Micropellets were allowed to coalesce for 24 hours after formation before saving day 0 samples (Fig. 1). On days 14 and 28, pellet samples were separated from the culture media and preserved in $-20^{\circ} \mathrm{C}$ for biochemical analyses. Media samples were saved to determine the amount of glycosaminoglycans released to the culture media.

\section{Study 2: Agarose culture}

Passaged NP and EP cells were trypsinized and encapsulated at $30 \times 10^{6}$ cells $/ \mathrm{mL}$ in $2 \% \mathrm{w} / \mathrm{v}$ agarose hydrogel (Fig. 1). Agarose (type 7-A; Sigma-Aldrich) was selected for its use in cartilaginous tissue regeneration, ${ }^{25}$ its compressive mechanical properties relative to human NP tissues, ${ }^{26}$ and biocompatibility. Constructs were cored from the cell-agarose slab ( $4 \mathrm{~mm}$ diameter, $2.3 \mathrm{~mm}$ thick). The compressive Young's modulus, $E_{\mathrm{Y}}$, was determined using unconfined compression stress relaxation using a custom-built mechanical loading device. A $0.5-\mathrm{g}$ tare load was applied and held for $5 \mathrm{~min}$, and then samples were loaded to $10 \%$ strain at a rate of $0.05 \%$ per second and held for $30 \mathrm{~min}$. Following stress-relaxation, the dynamic modulus was measured from the response to a superposed sinusoidal input of $\pm 1 \%$ strain at $0.5 \mathrm{~Hz}$ ( $n=5-6$ samples per group). Prior to biochemical analyses, construct wet weight was measured.

\section{Culture conditions}

Micropellets and agarose constructs were cultured in chemically defined media [CM: DMEM with $0.1 \mu \mathrm{M}$ dexamethasone, $40 \mathrm{mg} / \mathrm{mL}$ L-proline, $50 \mathrm{mg} / \mathrm{mL}$ ascorbate 2phosphate, $100 \mathrm{mg} / \mathrm{mL}$ sodium pyruvate, $1 \times \mathrm{ITS}+$ premix, $100 \mathrm{U} / \mathrm{mL}$ penicillin, and $100 \mathrm{mg} / \mathrm{mL}$ streptomycin and amphotericin B (Invitrogen Co.)] supplemented with $10 \mathrm{ng} / \mathrm{mL}$ of TGF- $\beta 3$ for the first 14 days of culture. Transient supplementation of TGF- $\beta 3$ was applied during the first 14 days of culture, based on previous studies that demonstrated improved matrix production under these conditions compared with continuous supplementation with TGF- $\beta 3 .{ }^{24,27,28}$ The osmolality of stock culture media was diluted to make 300 $\mathrm{mOsm} / \mathrm{kg}$ media by adding deionized, distilled water (starting osmolality $\sim 334 \mathrm{mOsm} / \mathrm{kg} \mathrm{H}_{2} \mathrm{O}$ ); then, sodium chloride $(\mathrm{NaCl})$ and potassium chloride $(\mathrm{KCl})$ were added to the media to make $400 \mathrm{mOsm} / \mathrm{kg}$ and $500 \mathrm{mOsm} / \mathrm{kg}$ media. The $\mathrm{pH}$ of the culture media was adjusted to 7.3 with sodium hydroxide $(\mathrm{NaOH})$ or hydrochloric acid $(\mathrm{HCl})$, and it was filtered with $0.22 \mu \mathrm{m}$ porous filters for sterilization.

\section{Biochemical analysis and statistics}

Pellet and agarose samples were prepared for biochemical analyses through proteinase $\mathrm{K}$ digestion. Biochemical analysis was performed for DNA, glycoamionglycan (GAG) and collagen ( $n=5$ per group per time point). DNA content was determined using the PicoGreen Kit (Invitrogen, Inc.). The GAG and collagen content were determined using the 1,9-dimethylmethylene blue and hydroxyproline assay, respectively. In the pellet study, GAG content was measured in the pellet and culture media. A one-way analysis of variance (ANOVA) was performed with factor of osmolality. Once significant was determined, a Tukey's post hoc analysis was performed, with significance assumed at $\alpha=0.05$. A Student's $t$-test was performed to compare the final DNA content at day 28 with the initial DNA content at day 0. Data are presented as mean \pm standard deviation.

\section{Results}

\section{Study 1: Micropellet culture}

Nucleus pulposus cells. Cell proliferation and division of juvenile and adult NP cells occurred throughout the 28day culture period for pellets in $300 \mathrm{mOsm} / \mathrm{kg}$ and 400 $\mathrm{mOsm} / \mathrm{kg}$ cultures ( 2 -way ANOVA $p$-time $<0.00001)$. The rate of cell division was dependent on the external osmotic loading condition, where cell proliferation decreased with increasing osmolality ( $p<0.01$; Fig. 2Aa, b). Juvenile NP cells cultured under long-term hyperosmotic conditions (500 mOsm $/ \mathrm{kg}$ ) had a DNA content that was significantly lower than the initial seeding density at day $0(p=0.03$ versus day 0 DNA; Fig. 2A, asterisk). In contrast, cell proliferation of juvenile and adult NP cells cultured at $300 \mathrm{mOsm} / \mathrm{kg}$ was significantly greater than the initial seeding density at day $0(p<0.0001$; Fig. 2A).

The total GAG content (i.e., media GAG + pellet GAG) of pellets from juvenile NP cells increased by an order of magnitude every 2 weeks ( $p$-time $<0.0001$; Fig. 2C, D). In contrast, matrix production for adult NP cells did not exhibit an exponential increase in GAG deposition (Fig. 2D). Total GAG production normalized by DNA content for juvenile 

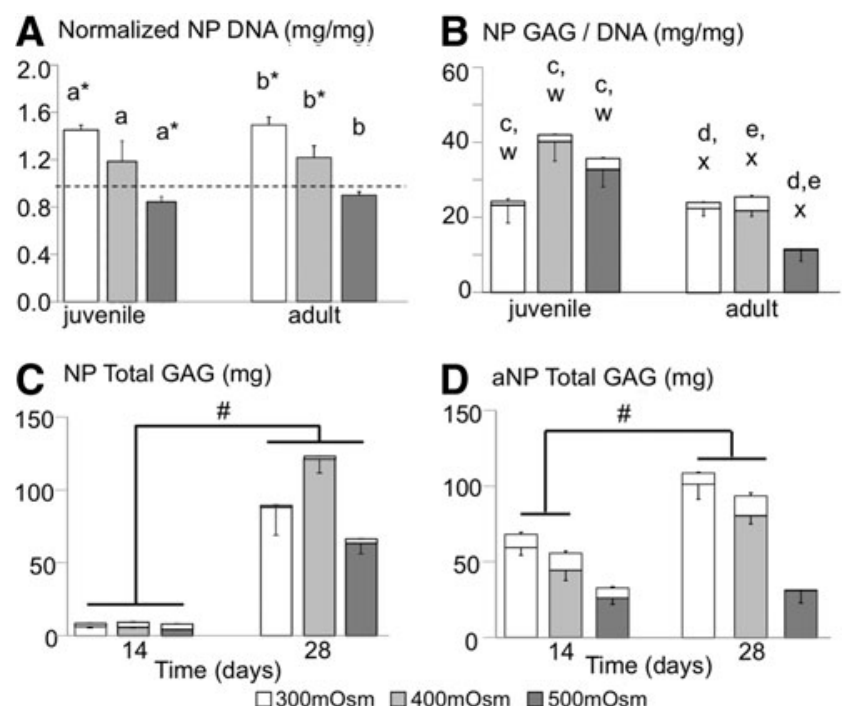

FIG. 2. (A) DNA content of juvenile and adult NP pellets at day 28 normalized to day 0 values. (B) Pellet glycoamionglycan (GAG) content normalized by DNA content for juvenile and adult NP cells. Total GAG content for $(\mathbf{C})$ juvenile NP cells and (D) adult NP cells. White caps at the top of each bar denote GAGs measured in the culture media. Groups with the same letter denote significant differences $(p \leq 0.05)$ with respect to osmotic loading condition. Labels $c-e$ denote differences in pellet GAG/DNA and $w$ and $x$ denote significant differences in media GAG/DNA $(p \leq 0.05)$. *Denotes differences with day 0 values and \# denotes differences in groups with respect to time (day 14 versus day 28).

$\mathrm{NP}$ cells was greatest for the $400 \mathrm{mOsm} / \mathrm{kg}$ culture condition ( $p \leq 0.04$; Fig. 2B). The amount of GAGs released into the culture media from juvenile NP pellets increased with hyperosmotic culture conditions ( $p<0.03$; Fig. 2Bx). The opposite trend was observed in GAG production from adult NP cells, where GAG production in the 300 and $400 \mathrm{mOsm} / \mathrm{kg}$ groups were significantly greater than the GAG production in the $500 \mathrm{mOsm} / \mathrm{kg}$ group $(p<0.0001$; Fig. 2B). The amount of GAGs measured in the media was less than $5 \%$ of the total GAG content at day 28 (Fig. 2B, white caps on bars).

For juvenile and adult NP pellets, there were no differences in the collagen content normalized by DNA content ( $p>0.9$; Fig. 3A, shown for juvenile pellets only). The

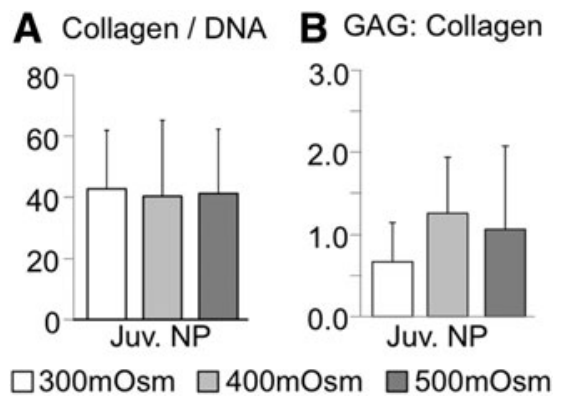

FIG. 3. (A) Collagen content normalized by DNA content and (B) GAG to collagen ratio for juvenile (Juv.) NP pellets. No significant differences were observed across osmotic loading conditions.
GAG to collagen ratio of NP pellets was approximately 1.0 and there were no significant differences with respect to osmotic loading ( $p>0.4$; Fig. 3B).

Endplate cells. Cell proliferation of juvenile EP cells in pellet culture was comparable to the NP cells, such that there was a decrease in cell proliferation with increasing osmolality. A Tukey's post-hoc analysis showed significant differences between the normalized DNA content of the hypo- and hyper-osmotic loading conditions $(300 \mathrm{mOsm} /$ $\mathrm{kg}$ vs. $500 \mathrm{mOsm} / \mathrm{kg} ; p=0.03$; Fig. 4Aa). The DNA content at day 28 was significantly higher than day 0 values for all osmotic loading conditions ( $p<0.01$; Fig. 4A, asterisks). Pellet and media GAG content normalized by DNA increased with hyperosmotic loading ( $p \leq 0.05$; Fig. 4B). There were no significant differences in the collagen content with osmotic loading ( $p \geq 0.06$; Fig. $4 \mathrm{C}$ ). The GAG to collagen content ratio was highest for the $400 \mathrm{mOsm} / \mathrm{kg}$ group $(p<0.01$; Fig. 4D) and was greater than the GAG to collagen ratio for NP cells under all loading conditions $(p<$ 0.01 ; Fig. 3B).

\section{Study 2: Hydrogel culture}

Long-term (42-day culture period) cell proliferation of juvenile and adult NP and juvenile EP cells encapsulated within agarose scaffolds decreased with increasing osmolality, which was comparable to observations from the pellet cultures $(p<0.03)$. Total GAG production for all three groups showed a trend for higher total GAG production in the 400 mOsm group; however, these differences were only significant in for the adult NP constructs (Fig. 5A-C).
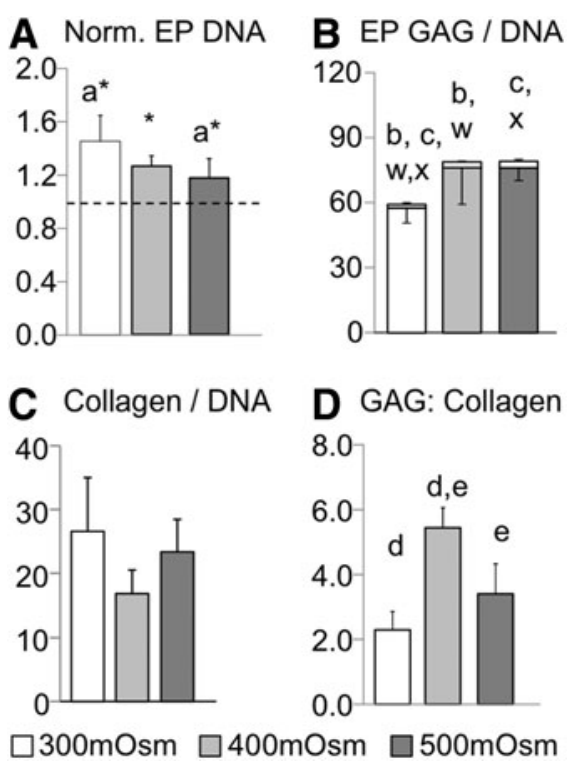

FIG. 4. Pellet results for juvenile EP cells. (A) Day 28 DNA content normalized to day 0 values. *Denotes differences between day 0 values. (B) GAG content normalized by DNA. White caps at the top of each bar denote the GAGs measured in the culture media. (C) Collagen content normalized to DNA content, and (D) GAG to collagen ratio at day 28 . Groups with the same letter $(a-e, w, x)$ denote significant differences with respect to osmotic loading condition $(p \leq 0.05)$. 

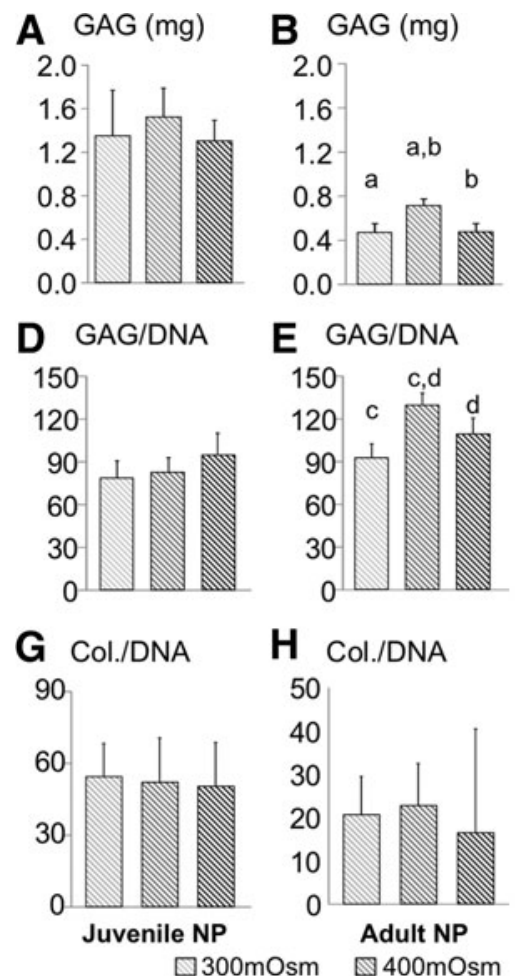
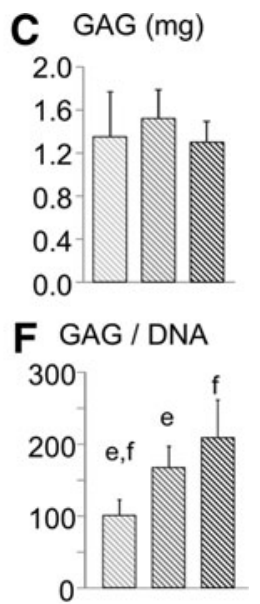

\section{Col./DNA}

50

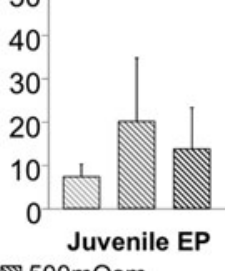

FIG. 5. Biochemical data for juvenile NP $(\mathbf{A}, \mathbf{D}, \mathbf{G})$, adult $\mathrm{NP}(\mathbf{B}, \mathbf{E}, \mathbf{H})$, and juvenile EP $(\mathbf{C}, \mathbf{F}, \mathbf{I})$ constructs. (A-C) Total GAG content measured in engineered constructs, (DF) GAG content normalized by DNA content, and (G-I) collagen content normalized by DNA content. Groups with the same letter $(a-f)$ denote significant differences with respect to osmotic loading condition.

For constructs encapsulated with juvenile NP cells, increases in normalized GAG content with osmotic loading was not as pronounced as pellet cultures ( $p \geq 0.1$; Fig. 5D vs. Fig. 2B). That is, there were no significant differences in the GAG content normalized by DNA ( $p>0.1$; Fig. 5D), wet weight $(3.45 \pm 0.82 \% / \mathrm{ww}$, pooled data; $p>0.3)$, and dry weight $(31.5 \pm 7.4 \% / \mathrm{dw} ; p \geq 0.1)$ for juvenile NP constructs with respect to the osmotic loading (Fig. 5D). The observed trend of GAG production from adult NP and juvenile EP cells encapsulated within the agarose hydrogel with respect to osmotic loading was similar to observations in pellet cultures. For adult $\mathrm{NP}$ constructs, the $400 \mathrm{mOsm} / \mathrm{kg}$ group had the highest GAG production when normalized by DNA content, wet weight, or dry weight ( $p \leq 0.04 ; 400 \mathrm{mOsm} / \mathrm{kg}$ group: $1.21 \pm$ $0.09 \% / w w, 35.4 \pm 1.3 \% / d w$; Fig. $5 B$ ). For juvenile EP constructs, the GAG content normalized by DNA increased with increasing osmolality $(p<0.03$; Fig. 5F); however, when normalized by wet or dry weight, there were no differences with respect to the external osmotic loading (3.82 \pm $0.76 \% / \mathrm{ww}, 40.1 \pm 7.2 \% / \mathrm{dw}$, pooled average; $p>0.1)$. The collagen content normalized by DNA content, wet weight, and dry weight followed a similar trend to the pellet cultures. That is, there were no significant differences in collagen production with respect to the external osmotic loading environment ( $p>0.15$; Fig. 5G-I).

The initial compressive Young's modulus was 9.45 \pm $2.77 \mathrm{kPa}$. At day 42, the final compressive Young's modulus

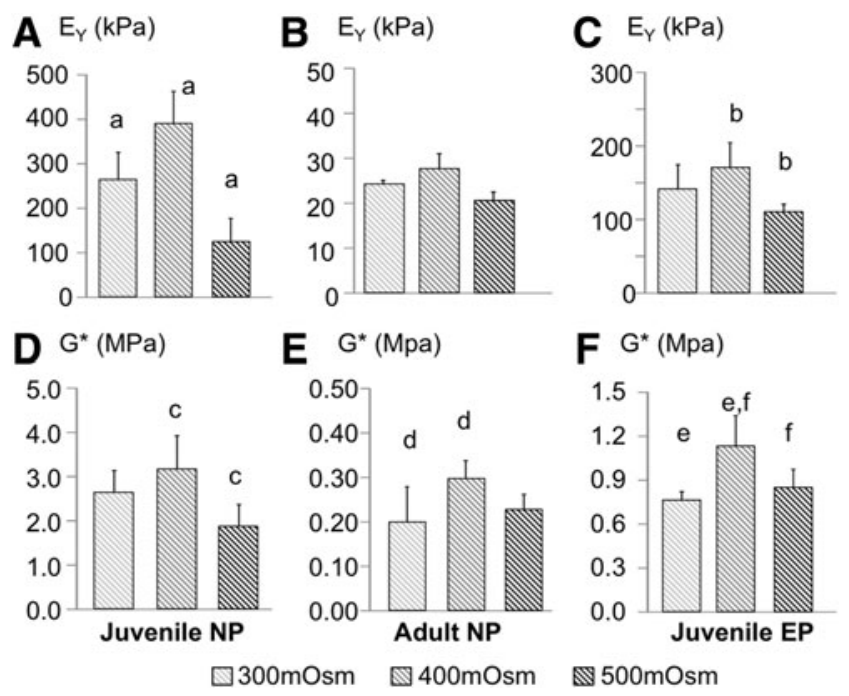

FIG. 6. Mechanical properties data for juvenile $\mathrm{NP}(\mathbf{A}, \mathbf{D})$, adult NP (B, E), and juvenile EP $(\mathbf{C}, \mathbf{F})$ constructs. (A-C) Compressive Young's modulus $\left(E_{\mathrm{Y}}\right)$ and $(\mathbf{D}-\mathbf{F})$ dynamic modulus $\left(G^{*}\right)$ at $0.5 \mathrm{~Hz}$. Groups with the same letter $(a-f)$ denote significant differences with respect to osmotic loading condition.

of juvenile NP cells was 10-40 times greater than the initial properties and was greater than the final Young's modulus of adult NP and juvenile EP constructs (Fig. 6A-C). The Young's modulus of all cell types followed a similar trend with stiffer properties at $400 \mathrm{mOsm} / \mathrm{kg}$; however, this trend was only significant for juvenile NP and EP cells ( $p<0.05$; Fig. 6A, Ca, b). The initial dynamic modulus of the agarose scaffold was $0.06 \pm 0.01 \mathrm{MPa}$ on day 0 . The final dynamic modulus for juvenile NP constructs was up to 50 times greater than day 0 values $(p<0.001$; Fig. 6D). For all cell types, the dynamic modulus was greatest for constructs cultured in the $400 \mathrm{mOsm} / \mathrm{kg}$ media $(p<0.05$; Fig. 6D-F).

\section{Discussion}

The intervertebral disc osmotic environment is altered dramatically with age, degeneration, and diurnal loading. A loss in water volume and proteoglycan content decreases the tissue's swelling capacity and alters the internal osmotic loading environment. Intervertebral disc tissue engineering and regenerative medicine strategies will require repair strategies that can withstand the disc's harsh in situ environment, which changes dramatically with diurnal loading and degeneration. This study evaluated the effect of longterm osmotic loading on structural and functional properties of de novo tissues produced by juvenile and adult disc cells acquired from bovine NP and EP tissues. Culturing disc cells under osmotic conditions that closely represent the in situ environment of healthy discs improved matrix production and mechanical function of engineered tissues (400 $\mathrm{mOsm} / \mathrm{kg}$ group).

Chondrocytes have been shown to behave as a pure osmolyte, such that cell volume is negatively correlated with the external osmotic environment. ${ }^{29,30}$ Changes in cell volume affects cellular mechanical forces and alters gene 
expression. ${ }^{6}$ In this study, EP cells were evaluated as a chondrocyte comparison to chondrocyte-like NP cells. Pellet and agarose cultures of juvenile NP and EP cells demonstrated similarities with respect to cell proliferation and functional mechanical properties (Figs. 2, 4, 6). The decrease in cell proliferation under hyperosmotic conditions agrees with previous work that demonstrated G2 arrest of NP cells in hyperosmotic conditions, preventing mitosis or cell division. ${ }^{31}$ GAG synthesis from juvenile NP and EP cells was greatest under hyper-osmotic conditions (Figs. 2B, 4B), which was comparable to the response observed by chondrocytes from articular cartilage. ${ }^{29}$ These results suggest a tradeoff between cell proliferation and matrix production under osmotic loading conditions. Furthermore, these findings demonstrate that tissue-engineering strategies used to improve cartilage tissue growth and development from juvenile chondrocytes may be applicable for juvenile NP tissue regeneration.

Disc degeneration has not been observed in mature bovine discs. Therefore, the bovine disc provides an ideal model for evaluating aging effects on matrix synthesis and tissue regeneration. GAG synthesis and compressive mechanical properties of adult NP constructs were highest at $400 \mathrm{mOsm} / \mathrm{kg}$ (Figs. 4, 5). These results differ from engineered tissues developed from adult chondrocytes from osteoarthritic articular cartilage, which had GAG deposition and compressive mechanical properties under hypoosmotic conditions (300 $\mathrm{mOsm} / \mathrm{kg}){ }^{32}$ Differences between the results reported here and those reported by Oswald et al. are likely due to culturing adult NP cells under transient growth factor supplementation (first 14 days) in this study, rather than with continuous growth factor supplementation. It is possible that there is an interaction between growth factor supplementation and osmotic loading on matrix production, which will be evaluated in future work.

Pellet and agarose cultures of juvenile NP and EP cells were similar with respect to osmotic loading conditions. However, differences were observed between pellet and agarose cultures with adult NP cells. In pellet cultures, GAG production of adult NP pellets was greatest under hypoosmotic conditions (Fig. 2B). In contrast, adult NP cells encapsulated in agarose had higher GAG deposition and compressive mechanical properties in the $400 \mathrm{mOsm} / \mathrm{kg}$ group. The differences between pellet and agarose culture may be due to differences in cell-cell interactions; however, Munir et al. demonstrated similar gene expressions from stem cells cultured in pellet and scaffold cultures. ${ }^{33}$ Alternatively, differences between adult NP pellet and agarose culture may be due to differences in the size of proteoglycans synthesized during early culture periods, or due to spatial differences in the construct biochemical composition, which could not be ascertained with the assays performed in this study. Sztrolovics and coworkers demonstrated that versican molecules from articular cartilage $(>200 \mathrm{kDa})$ were $4 \times$ greater than the versican measured from postnatal intervertebral discs $(50 \mathrm{kDa}){ }^{34}$ During the first two weeks of pellet cultures, $15 \%-20 \%$ of the GAGs were lost to the surrounding culture media (data not shown). Taken together, it is possible that matrix production in pellet and agarose cultures is comparable; however, the loss of early matrix results in large differences in the functional engineered tissue composition.
There were some notable differences between the tissue growth data reported in this study and data reported in previous studies. Engineered cartilage constructs often report a strong correlation between normalized GAG deposition and compressive Young's modulus, which was not the case for juvenile NP engineered tissues in this study (Fig. 5D vs. Fig. 6A). The differences between engineered tissues developed by chondrocytes and NP cells may be due to differences in tissue organization (i.e., crosslinking) or the types of proteins synthesized during culture (i.e., aggrecan, versican, collagen 1, or collagen 2). Moreover, previous studies demonstrated that short-term osmotic loading $(<7$ days at 500 $\mathrm{mOsm} / \mathrm{kg}$ ) alters cell volume, ${ }^{35}$ increased gene expression of aggrecan and collagen type 2, and decreases collagen type 1 expression from skeletally mature (i.e., adult) disc cells. ${ }^{6,36}$ The results from this study demonstrated that GAG synthesis from adult NP cells was greater in the $400 \mathrm{mOsm} /$ $\mathrm{kg}$ group for pellets and agarose cultures (Figs. 2B, 5B). The differences observed between the findings reported here and previous studies may be due to culture duration. Furthermore, an increase in gene expression does not necessarily translate to direct correlation in protein production, which may result in differences between studies. ${ }^{5}$ Future work will focus on further characterizing the matrix composition and structure.

Tissue regeneration and disc explant culture has not been trivial, due to the tissue's excellent swelling capability, hypoxic environment in vivo, and limited passive nutrient diffusion. Disc explants have been cultured in hyperosmotic conditions to effectively decrease tissue swelling. ${ }^{37}$ However, long-term culture in hyperosmotic conditions results in a decrease in cell proliferation (Figs. 2A, 4A), which agrees with previous studies on stem cells and chondrocytes. $^{24,38,39}$ Therefore, maintaining disc cell homeostasis, tissue composition, and mechanical function during longterm explant cultures may require low physiological loading rather than hyperosmotic loading conditions. ${ }^{40,41}$

Recent studies have focused on using regenerative medicine strategies to develop a biological treatment option for painful disc degeneration. ${ }^{42}$ These techniques will need to restore the biochemical composition and mechanical function of the tissue. In this study, engineered disc tissues were cultivated using juvenile and adult disc cells from nondegenerated tissues. The biochemical composition achieved in engineered tissues was approximately $20 \%$ of native values, demonstrating the challenge in cultivating de novo $\mathrm{NP}$ tissues in vitro. It is possible that further tissue growth can be improved through dynamic loading or through additional growth factor stimuli, ${ }^{\dagger}, 43$ which will be evaluated in future work. In conclusion, culturing disc cells in an osmotic environment that best mimics the healthy disc environment (400 $\mathrm{mOsm} / \mathrm{kg}$ ) may be ideal for balancing cell proliferation, matrix production, and mechanical properties of engineered disc tissues.

*O'Connell GD, Tan AR, Palmer G, et al. Cell migration behavior of human chondrocytes for guiding three dimensional engineered cartilage growth. In review.

$\dagger$ O'Connell GD, Kelly TN, Roach BR, et al. Dynamic loading with chondroitinas-ABC improves collagen properties in engineered cartilage. In review. 


\section{Acknowledgments}

The authors would like to thank Clark T. Hung, PhD, for use of his laboratory for data collection and tissue culture. This work was supported by a Postdoctoral Professional Development and Enrichment Award from the Federation of American Societies for Experimental Biology.

\section{Author Disclosure Statement}

The authors certify that there is no conflict of interest related to the work presented in this manuscript.

\section{References}

1. Elliott DM, Setton LA. Anisotropic and inhomogeneous tensile behavior of the human anulus fibrosus: experimental measurement and material model predictions. J Biomech Eng 2001;123:256-263.

2. Johannessen W, Elliott DM. Effects of degeneration on the biphasic material properties of human nucleus pulposus in confined compression. Spine 2005;30:E724-E729.

3. O'Connell GD, Guerin HL, Elliott DM. Theoretical and uniaxial experimental evaluation of human annulus fibrosus degeneration. J Biomech Eng 2009;131:111007.

4. O'Connell GD, Vresilovic EJ, Elliott DM. Comparison of animals used in disc research to human lumbar disc geometry. Spine 2007;32:328-333.

5. Neidlinger-Wilke C, Mietsch A, Rinkler C, et al. Interactions of environmental conditions and mechanical loads have influence on matrix turnover by nucleus pulposus cells. J Orthopaed Res 2012;30:112-121.

6. Wuertz K, Urban JP, Klasen J, et al. Influence of extracellular osmolarity and mechanical stimulation on gene expression of intervertebral disc cells. J Orthopaed Res 2007;25: 1513-1522.

7. Antoniou J, Steffen T, Nelson F, et al. The human lumbar intervertebral disc: evidence for changes in the biosynthesis and denaturation of the extracellular matrix with growth, maturation, ageing, and degeneration. J Clin Invest 1996;98:996-1003.

8. Chelberg MK, Banks GM, Geiger DF, et al. Identification of heterogeneous cell populations in normal human intervertebral disc. J Anat 1995;186:43-53.

9. Urban JP, McMullin JF. Swelling pressure of the inervertebral disc: influence of proteoglycan and collagen contents. Biorheology 1985;22:145-157.

10. Urban JP, Roberts S, Ralphs JR. The nucleus of the intervertebral disc from development to degeneration. Amer Zool 2000;40:53-61.

11. Boos N, Wallin A, Gbedegbegnon T, et al. Quantitative MR imaging of lumbar intervertebral disks and vertebral bodies: influence of diurnal water content variations. Radiology 1993;188:351-354.

12. Sivan S, Neidlinger-Wilke C, Wurtz K, et al. Diurnal fluid expression and activity of intervertebral disc cells. Biorheology 2006;43:283-291.

13. Kraemer J, Kolditz D, Gowin R. Water and electrolyte content of human intervertebral discs under variable load. Spine 1985;10:69-71.

14. Ishihara H, Warensjo K, Roberts S, et al. Proteoglycan synthesis in the intervertebral disk nucleus: the role of extracellular osmolality. Am J Physiol 1997;272:C1499-C506.

15. Maroudas A. Biophysical chemistry of cartilaginous tissues with special reference to solute and fluid transport. Biorheology 1975;12:233-248.
16. Urban JP, Maroudas A, Bayliss MT, et al. Swelling pressures of proteoglycans at the concentrations found in cartilaginous tissues. Biorheology 1979;16:447-464.

17. O'Connell GD, Jacobs NT, Sen S, et al. Axial creep loading and unloaded recovery of the human intervertebral disc and the effect of degeneration. J Mech Behav Biomed Mat 2011;4:933-942.

18. Hunter CJ, Matyas JR, Duncan NA. Cytomorphology of notochordal and chondrocytic cells from the nucleus pulposus: a species comparison. J Anat 2004;205:357362.

19. Spillekom S, Smolder L, Grinwis G, et al. Increased osmolarity and cell clustering preserves canine notochordal cell phenotype in culture. Tissue Engineering. Part C, Methods 2014;20:652-662.

20. Horner HA, Roberts S, Bielby RC, et al. Cells from different regions of the intervertebral disc: effect of culture system on matrix expression and cell phenotype. Spine 2002;27:1018-1028.

21. Melrose J, Smith S, Ghosh P. Differential expression of proteoglycan epitopes by ovine intervertebral disc cells. J Anat 2000;197:189-198.

22. Takeno K, Kobayashi S, Negoro K, et al. Physical limitations to tissue engineering of intervertebral disc cells: effect of extracellular osmotic change on glycosaminoglycan production and cell metabolism. Laboratory investigation. J Neurosurg Spine 2007;7:637-644.

23. Wuertz K, Godburn K, Neidlinger-Wilke C, et al. Behavior of mesenchymal stem cells in the chemical microenvironment of the intervertebral disc. Spine 2008;33:1843-1849.

24. Sampat SR, O'Connell GD, Fong JV, et al. Growth factor priming of synovium-derived stem cells for cartilage tissue engineering. Tissue Eng Part A 2011;17:2259-2265.

25. O'Connell GD, Lima EG, Bian L, et al. Toward engineering a biological joint replacement. J Knee Surg 2012;25: 187-196.

26. Cloyd JM, Malhotra NR, Weng L, et al. Material properties in unconfined compression of human nucleus pulposus, injectable hyaluronic acid-based hydrogels and tissue engineering scaffolds. Eur Spine J 2007;16:1892-1898.

27. Byers BA, Mauck RL, Chiang IE, et al. Transient exposure to transforming growth factor beta 3 under serum-free conditions enhances the biomechanical and biochemical maturation of tissue-engineered cartilage. Tissue Eng Part A 2008;14:1821-1834.

28. Huang AH, Stein A, Tuan RS, et al. Transient exposure to transforming growth factor beta 3 improves the mechanical properties of mesenchymal stem cell-laden cartilage constructs in a density-dependent manner. Tissue Eng Part A 2009;15:3461-3472.

29. Sampat SR, Dermksian MV, Oungoulian SR, et al. Applied osmotic loading for promoting development of engineered cartilage. J Biomech 2013;46:2674-2681.

30. Urban JP. The chondrocyte: a cell under pressure. Brit $\mathbf{J}$ Rheumatol 1994;33:901-908.

31. Mavrogonatou E, Kletsas D. High osmolality activates the G1 and G2 cell cycle checkpoints and affects the DNA integrity of nucleus pulposus intervertebral disc cells triggering an enhanced DNA repair response. DNA Repair 2009;8: 930-943.

32. Oswald ES, Ahmed HS, Kramer SP, et al. Effects of hypertonic $(\mathrm{NaCl})$ two-dimensional and three-dimensional culture conditions on the properties of cartilage tissue engineered from an expanded mature bovine chondrocyte source. Tissue Eng Part C Methods 2011;17:1041-1049. 
33. Munir S, Foldager CB, Lind M, et al. Hypoxia enhances chondrogenic differentiation of human adipose tissuederived stromal cells in scaffold-free and scaffold systems. Cell Tissue Res 2014;355:89-102.

34. Sztrolovics R, Grover J, Cs-Szabo G, et al. The characterization of versican and its message in human articular cartilage and intervertebral disc. J Orthopaed Res 2002;20:257-266.

35. Pritchard S, Guilak F. The role of F-actin in hypo-osmotically induced cell volume change and calcium signaling in anulus fibrosus cells. Ann Biomedl Eng 2004;32:103-111.

36. Chen J, Baer AE, Paik PY, et al. Matrix protein gene expression in intervertebral disc cells subjected to altered osmolarity. Biochem Biophys Res Co 2002;293:932-938.

37. van Dijk BG, Potier E, Ito K. Long-term culture of bovine nucleus pulposus explants in a native environment. Spine J 2013;13:454-463.

38. Liang C, Li H, Tao Y, et al. Responses of human adiposederived mesenchymal stem cells to chemical microenvironment of the intervertebral disc. J Transl Med 2012;10:49.

39. Mavrogonatou E, Kletsas D. Effect of varying osmotic conditions on the response of bovine nucleus pulposus cells to growth factors and the activation of the ERK and Akt pathways. J Orthopaed Res 2010;28:1276-1282.

40. Gantenbein B, Grunhagen T, Lee CR, et al. An in vitro organ culturing system for intervertebral disc explants with vertebral endplates: a feasibility study with ovine caudal discs. Spine 2006;31:2665-2673.

41. Walter BA, Illien-Junger S, Nasser PR, et al. Development and validation of a bioreactor system for dynamic loading and mechanical characterization of whole human intervertebral discs in organ culture. J Biomech 2014;47:20952101.

42. Smith LJ, Nerurkar NL, Choi KS, et al. Degeneration and regeneration of the intervertebral disc: lessons from development. Dis Model Mech 2011;4:31-441.

43. Tan AR, Alegre-Aguaron E, O'Connell GD, et al. Passagedependent relationship between mesenchymal stem cell mobilization and chondrogenic potential. Osteoarthr Cartilage 2014. In press.

Address correspondence to:

Grace D. O'Connell, PhD Department of Mechanical Engineering University of California, Berkeley 5122 Etcheverry Hall, \#1740 Berkeley, CA 94720

E-mail: g.oconnell@berkeley.edu 